\title{
MACRO WASTE ON BENIN BEACHES
}

\author{
DOSSOU-YOVO Coffi Adrien \\ Urban and Regional Dynamics Studies Laboratory (LEDUR) \\ Institute of Geography, Spatial Planning and the Environment (IGATE) \\ University of Abomey-Calavi, (Republic Of Benin) \\ https://doi.org/10.35410/IJAEB.2021.5638
}

\begin{abstract}
A massive and recurring planetary phenomenon, the presence of macro-waste on beaches affects all coastline. Awareness of the environmental and economic impacts generated by this type of waste originates many initiatives, including the mobilization of international agencies which call for bold measures to mitigate the pollution of seas and coasts by the macro waste. What is the current status of this particular form of pollution in Benin beaches?

This paper aims at answering this question through the analysis of the specificities of this source of pollution, the origins and composition of the releases, the factors variability factors of deposits in time and space as well as the related externalities.
\end{abstract}

Keywords: Beninese beaches, Macrowaste, Externalities.

\section{INTRODUCTION}

The presence of these discharges on beaches is a massive and recurring planetary phenomenon that spares no coast (D. A. K. Barnes, 2002, p. 809; UNEP, 2009. P, 7). The very slow process of their degradation, combined with the ever increasing quantity of waste discharged, leads to a regular increase in the deposit of macro-waste in the oceans and on the shores (L. Cannizzaro et al, 1995, p. 1412). The question of macro-waste at the crossroads of natural and social sciences since environmental problems are the consequence of individual and public social behavior.

For a long time and despite the scientific studies carried out on the subject for almost 30 years, the problem of macro-waste was mainly considered in terms of aesthetic impact. However, the societal and legal context is now propelling macro-waste to the rank of an emerging theme with the awareness of the environmental and economic impacts generated by this pollution problem is at the origin of many initiatives, starting with the mobilization of international bodies which call for bold measures to reduce marine pollution by macro-waste (UNEP, 2009. P, 13: IISD, 2016, p. 9). Since then, the scientific community has been working to develop methods that are best suited to better understand this phenomenon. What is the state of play of this particular form of pollution on the Benin coast?

The present article proposes to provide some answers to this question, through the specificities of this form of pollution, the origins and the composition of the discharges, the factors of variability of deposits in time and space, the externalities linked to the presence of this waste. 
Vol. 06, No. 03; 2021

ISSN: $2456-8643$

\subsection{Macro-waste, a polysemic phenomenon}

The literature review shows that the perception of the macro-waste issue is extremely heterogeneous. There is therefore no exact definition of the term "macro-waste" either in national or European bodies. Only the functional criterion "abandonment of the object in question" makes it possible to determine whether it is waste or not. Several definitions, which may contradict each other, have therefore emerged. According to CEDRE, macro-waste is waste of all kinds, of varied form and of both human and natural origin, floating in the sea or deposited on the coast. The RAMOGE agreement defines it as solid waste of human origin, visible to the naked eye, abandoned on the coast, floating on the surface or submerged.

The definition used in this article is the most commonly cited. It is attributed to UNEP (United Nations Environment Program) which defines waste in aquatic environments as:

"[...] Objects manufactured and used for the benefit of humanity [...] voluntarily thrown directly into the sea, in rivers or on beaches, or [...] taken via rivers, wastewater treatment networks sewage, storm or wind basins; they may also have been intentionally abandoned on beaches or the coast or even been lost at sea unintentionally, for example in periods of heavy weather [...]. This is "[...] solid waste visible to the naked eye."(SAFEGE / ADEME, 2012, p. 11)

This definition does not include waste that is very small, microscopic, or dissolved substances that can cause pollution, and imperceptible to the human eye.

In addition, several macro-waste classification systems are used on a recurring basis. A first system is based on the types of constituent materials (plastic, glass, metals, wood, textiles, paper, etc.). A second system is based on the emitting activities (for example, fishing waste, shellfish waste, recreational waste, etc.) A third classification system is based on the possible future of the waste, we then speak of recoverable or non-recoverable waste. Some specialists (Ryan et al. 2009, p. 1923; Thompson et al. 2009, p. 1975) use height as a classification criterion. These distinguish mega-waste whose size is greater than $100 \mathrm{~mm}$ in diameter, macro-waste is greater than $20 \mathrm{~mm}$ in diameter, meso-waste is between 5 and $20 \mathrm{~mm}$ and micro-waste has a size that remains less than $5 \mathrm{~mm}$.

This diversity in the way of defining and classifying macro-waste calls for several remarks. First, this denotes a heterogeneity in the overall perception of the issues relating to them. These definitions and classifications apply both to so-called anthropogenic waste (generated by humans and their activities) and to waste of natural origin (algae, wood or animal corpses), without any real distinction. There is confusion over the status to be given to macro-waste or, quite simply, a divergence of interest when it comes to categorizing this waste. Finally, it should be noted that macro-waste is often characterized as a 'visual nuisance' and not as a type of pollution

\subsection{The beach, a unique site for macro-waste}

Beninese beaches, like all the others, are privileged places for depositing macro-waste. They are an integral part of the margino-littoral stricto sensu, a geographical area stretching from HillaCondji in the west (border with Togo) to Kraké in the east (border with Nigeria). This space is unique in more than one way. The first originality of this environment is due to its location, at the limit between the sea and the emerged lands. It is also due to its geometry (narrow strip of it is a narrow strip about 125 kilometers long but only a few meters wide). But in a specific way, the area of manifestation of the phenomenon of macro-waste, strictly speaking, is the tidal zone, 
Vol. 06, No. 03; 2021

ISSN: $2456-8643$

also called the foreshore. This very particular space, at the interface between the marine environment and the terrestrial environment, is often understood as a system with multiple elements, but the two main components of which are the ecosystem (an environment with various potentialities and strong physical constraints and the sociosystem (a combination of factors that relate to society). The dynamics of the system resulting from complex interactions between natural dynamics and social dynamics (Mirault, 2007; Mirault and David, 2009). Major physical discontinuity of the terrestrial space which results in very unique morphological, economic, sociological, legal and landscape characteristics, mainly induced by the presence of the sea (Jean-Pierre Corlay 1995 p. 249). Considering these specificities, the beaches receive all kinds of waste, generally taken out of traditional waste management circuits and which end up on the beaches ages. (ADEME, 2012, p. 11). The beaches have thus become "the ultimate receptacle for all the waste of human activity" (B. Burgenmeier, 2000, p. 20).

\subsection{A deposit dependent on hydrometeorological dynamics}

On the Beninese coasts, the deposit of macro waste depends on the interactions of three main factors: watercourses, wind and marine currents. Watercourses (Mono, Ouémé mainly) constitute the main vector of circulation of waste from all kinds of towns crossed towards the coast. Rainfall also plays an important role firstly by causing floods which carry with them plant debris as well as elements of wild dumps located on the major bed; then, by causing the overflow of certain sewerage networks, the detritus present in the water then no longer being stopped by the screening installations.

Once in the coastal environment, macro-waste deposits are dependent on tides, swells and winds which subject them to phenomena of concentration or dispersion. The deposits experience a variation of $20 \%$, going from 5.1 tonnes to 3.8 tonnes per trip, i.e. a coefficient of variation of the weight of the deposit oscillating between 5\% and 38\% depending on the types of debris. The most abundant deposits are recorded during periods of high amplitude hydrometeorological forcing. Likewise, debris does not present the same vulnerability to transport factors. The lightest debris (plastics, textiles, paper and plants) show the greatest variations (between 15\% and 38\%) on the entire coastline. Light objects (plastics, textiles) are more present in the deposit of fattening beach sectors (Adounko-Plage and West sectors of the Port of Cotonou) and at the mouths (between $80 \%$ and $90 \%$ of the deposit, against $63 \%$ on average for the group). On the other hand, heavy objects such as metals and glasses have a significantly higher than average presence in the eroding sectors (between the border of Togo and the locality of Djondji and east of the Port of Cotonou on the border of Nigeria) than anywhere else on the beach. The most abundant strandings are recorded in coastal sectors characterized by their proximity either to large urban and peri-urban centers or to estuaries. The concentration of debris is also dependent on the sediment balance. Sectors in fattening or in dynamic equilibrium (35\% of the coastline) concentrating $75 \%$ of the deposit of macro-waste. The latter also varies according to the lateral profile of the foreshore (from the shore line to the top of the beach). The deposits are made on three lines: the first is made up of the deposits of the very last tide, the second line corresponds to those of the highest tides and the last line corresponds to the area of flight and trapping of light waste. In general, the heaviest wastes remain at the upper limit of the shore, while the lighter ones fly to land where they are sometimes trapped in crevices in the relief or by vegetation. 
Finally, a phenomenon of "invisible deposit" takes place. The wind and the sea also transport and deposit sediments (sand) which bury beach waste.

\subsection{Rejects with multiple origins, but predominantly human}

It is commonly accepted in the international bibliography that approximately $70 \%$ to $80 \%$ of the waste found in the seas and on the coast is of land-based origin and that the remainder comes from maritime activities. A study carried out exclusively on the coasts of more than one hundred countries by International Coastal Cleanup shows that nearly $60 \%$ of the waste collected on the beaches comes directly from the activities carried out on site

But whatever the origin of the waste (marine, coastal or continental), the cause of their presence on the coast is essentially human (accidental or negligent loss, illegal discharges, voluntary abandonment, etc.), just like waste from strictly terrestrial origin which, thrown away, abandoned, or poorly stored, are taken up by natural elements (flight, leaching of roads, erosion of landfills, etc.). Exceptional natural, meteorological or hydrological events can also generate significant accumulations of waste on the coast (breakage, tearing off during tornadoes, floods). (Kerambrun and E. Evrard p.1).

The results of the rare work to characterize beach waste on Benin's coasts (Hounguè, 2016; Dossou-Yovo 2017), confirm the different sources of macro-waste on the beaches described above as shown in figure 1.

Figure 1: Origins of beach waste
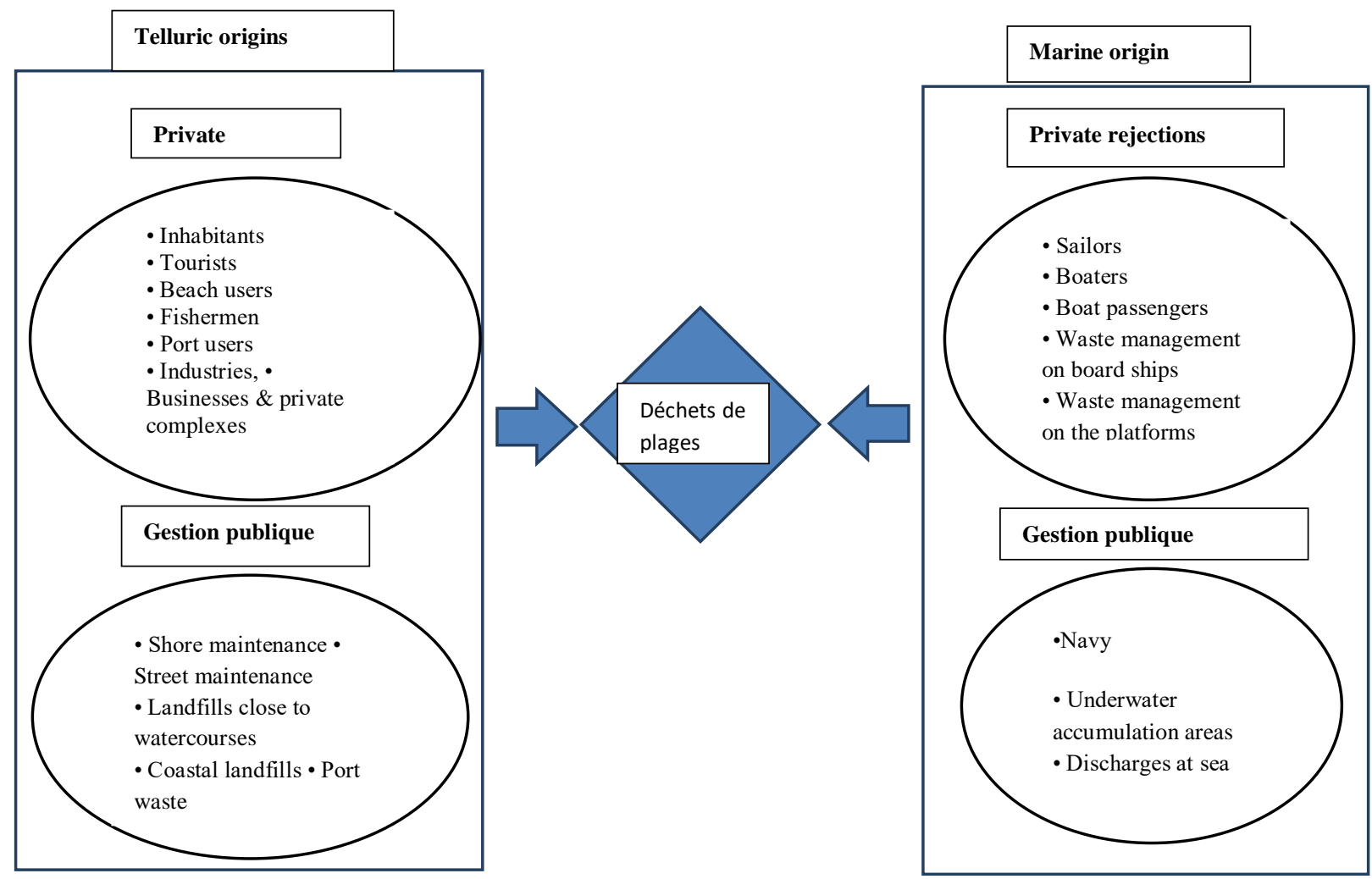
Source: HENRY Maryvonne, 2010 adapted by Dossou-Yovo

Figure 1 confirms the extreme diversity of actors behind the production of waste. The first group of players is made up of beach users (bathers, walkers, picnickers, water sports enthusiasts who neglect or voluntarily abandon waste on the coast). Then come the ports of Cotonou (autonomous port and fishing port) whose activities generate large quantities of waste of all kinds, from the handling of cargoes on docks and ships (despite national regulations and international conventions which ban such practices), fishing activities, boat maintenance on the refit areas, but also the abandonment of household waste. There are also domestic, agricultural and industrial activities. Fishing activity also generates waste which often ends up washing up on beaches (ropes, pots, buoys, nets, polystyrene and cans). Similarly, as pointed out previously, illegal dumps, located near the rivers and on the coast represent an important source of inflows of waste that ends up on the beaches.

Analysis of the macro-waste deposit indicates a preponderance of releases from human activity and poorly biodegradable materials (photo 1 ).

Photo 1: Overview of discharges collected on Beninese beaches

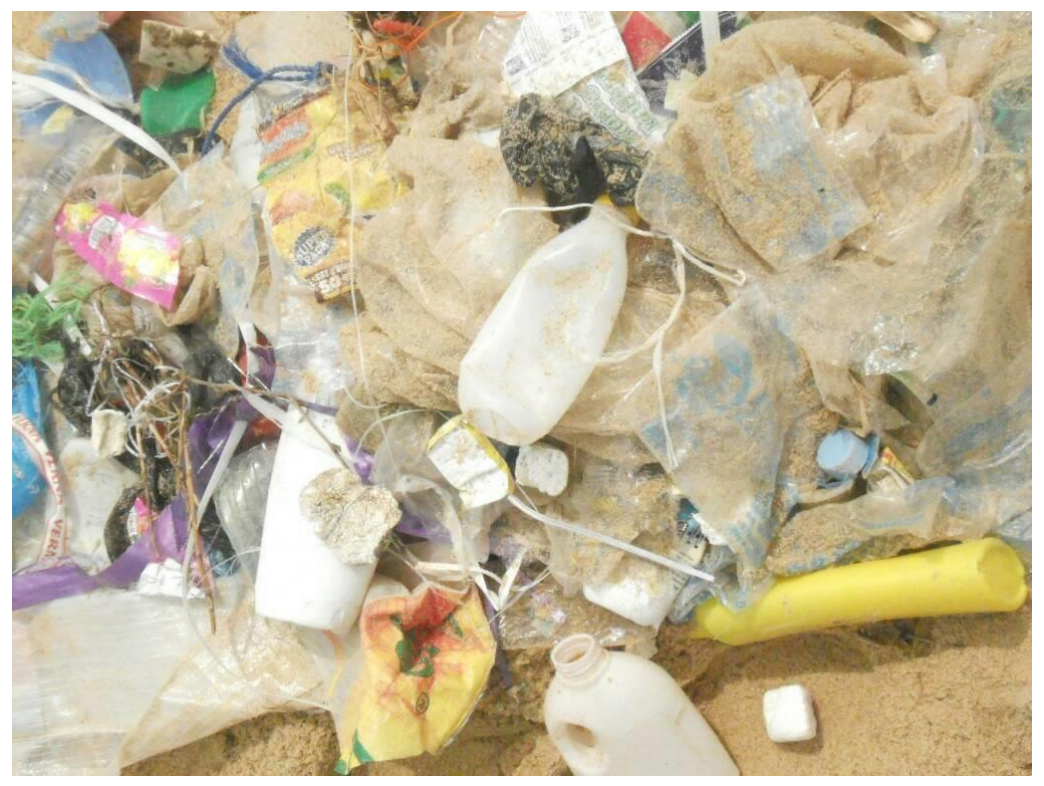

Source: Dossou-Yovo A. March 2021

Photo 1 shows that the deposit is made of plastic and polystyrene (yogurt pots, bottle, gloves, vegetable bag / net, oil can, lids, pen, comb, brush, toys, film, nets and ropes, floats, buoys, etc.); textiles (clothing, burlap bag, etc.); paper and cardboard (cardboard, food box / pack, cigarette packs, cigarette filters, newspaper and magazines, etc.); metals (aerosol can, spray bottle, capsules, beverage can, electrical accessory, aluminum packaging, tin can, scrap metal, keg, paint cans, wire, wire netting, etc.); glasses (bottle, broken bottles, neon bulb or tube, etc.); the other types of waste being tapes, tires, belts, used condoms, pottery / ceramics, building materials, etc. Figure 3 shows the share of each type of material in the macro-waste deposit. 
Figure 2: Composition of the deposit of beach waste

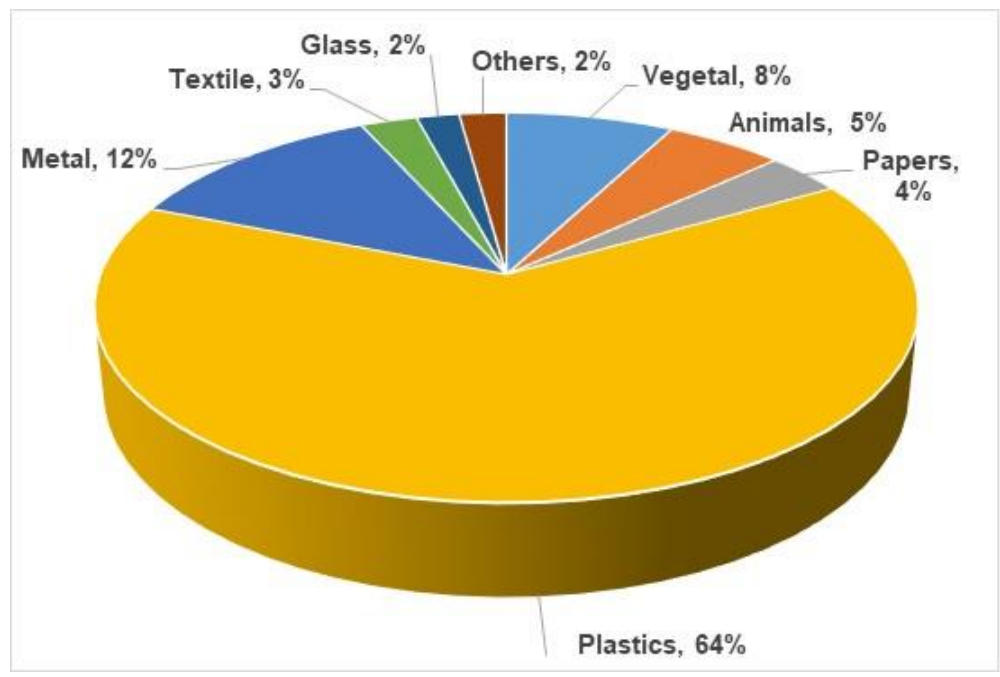

Source : Dossou-Yovo, 2017

The analysis in Figure 2 reveals that the deposit of beach discharges is characterized by waste from human activity, regardless of the beach sector considered. There is a preponderance of food packaging or waste linked to human activities carried out on land, including on the coast. Plastic objects represent $64 \%$ against $12 \%$ for metals. Materials of biological origin represent around $16 \%$ of all waste.

Finally, waste of natural origin made up of wood brought in by rivers and the carcasses of marine animals. In this category, we must mention the case of immense banks of algae which seasonally invade Beninese beaches. These are in particular the species Sargassum fluitans and Sargassum natans, which vary in color from yellow-brown to dark brown when they dry on beaches (Plate 1).

Plate 1: Invasion of Beninese beaches by seaweed

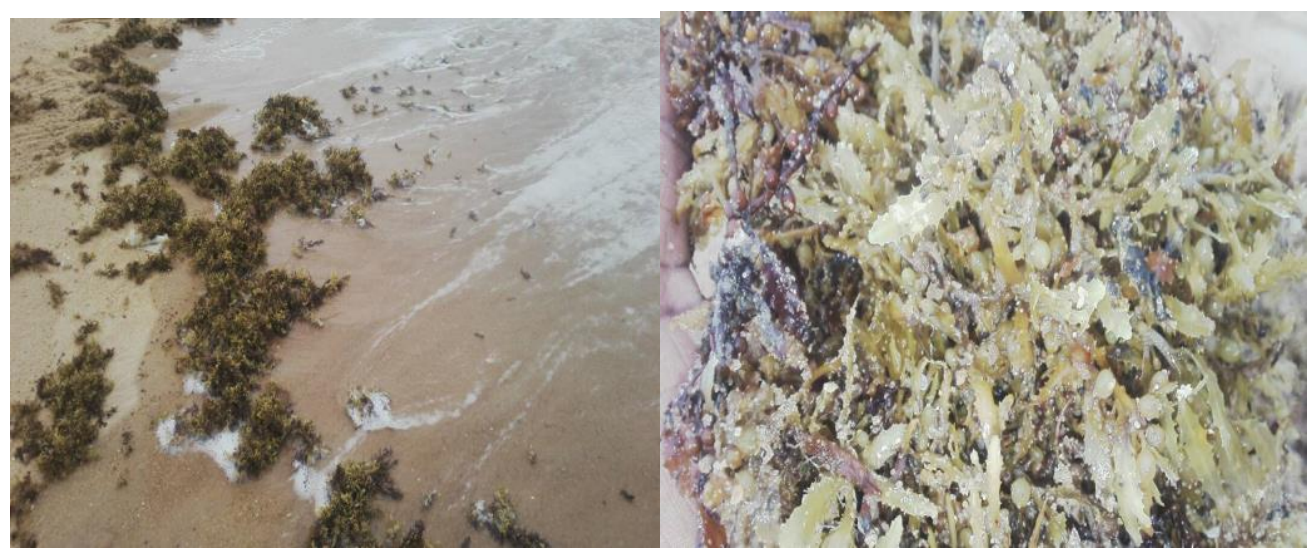


(Dossou-Yovo shot, April 2017)

This massive phenomenon, first observed in 2011, is repeated every year between March and April. The weight of these seaweed washed up on the beaches is 250 kilograms per kilometer of beach and per tide, which represents more than $85 \%$ of the natural sea leashes on the Beninese coasts (Hounguè 2016, p. 48 and Dossou-Yovo, 2017, p 62.).

\subsection{Multiple and varied induced externalities}

In the current state of knowledge, very direct damage caused to fauna and flora by macro-waste (entanglement of animals in pieces of waste, lost nets, being trapped in thongs and cans of drink and ropes or strings that can cause flesh injuries, strangulation and death.

Nuisances for marine fauna in the coastal environment have also been observed, in particular with plastic waste which is particularly dangerous for marine animals (suffocation due to residues of fishing equipment such as nets and ropes, or ingestion of packaging plastics causing death by intestinal obstruction). In addition, certain species such as marine mammals, turtles, invertebrates and crustaceans (octopus, jellyfish, crabs), and even birds can get entangled in pieces of waste, lost nets, be trapped in thongs, packaging systems for beverage cans and ropes or twine (see photo 2).

Photo 2: Effects of macro-waste from beaches on wildlife

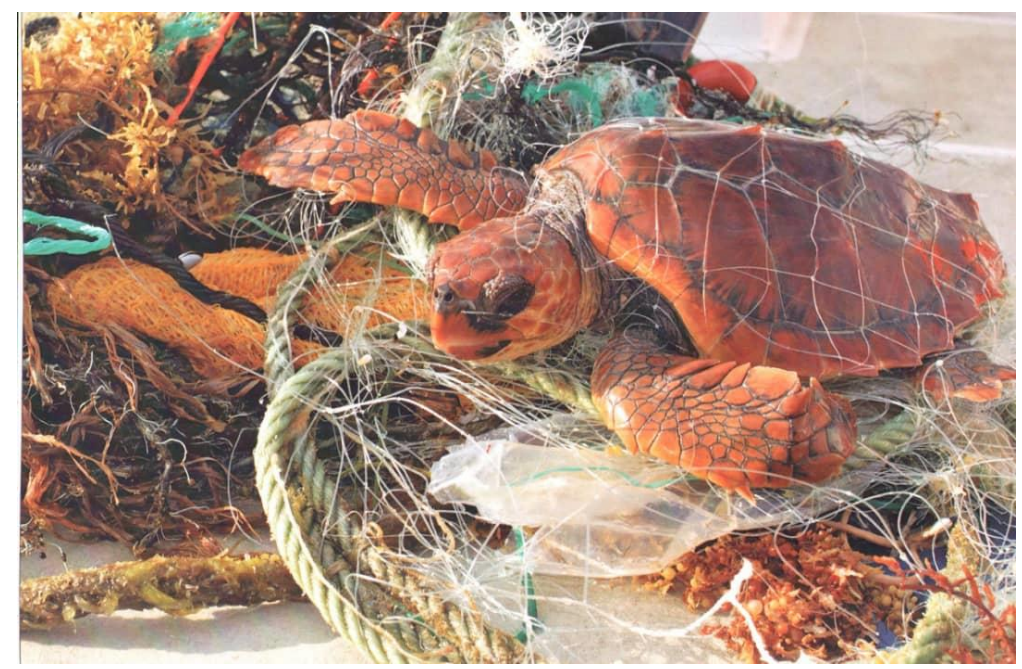

Source: Nature Tropicale info N0 97 of March 2020

The photo shows turtles trapped in nets and ropes. This can be a significant factor in serious injury or death from strangulation or immobilization.

Economically, the externalities linked to macro-waste are more difficult to assess. It is however accepted that the discharge of waste into aquatic environments has a significant economic impact on the professional activities which depend on it, in particular that of fishing, whether in river or marine environment. 
Figure 3: Nuisances caused by macro-waste according to users of beaches in Benin

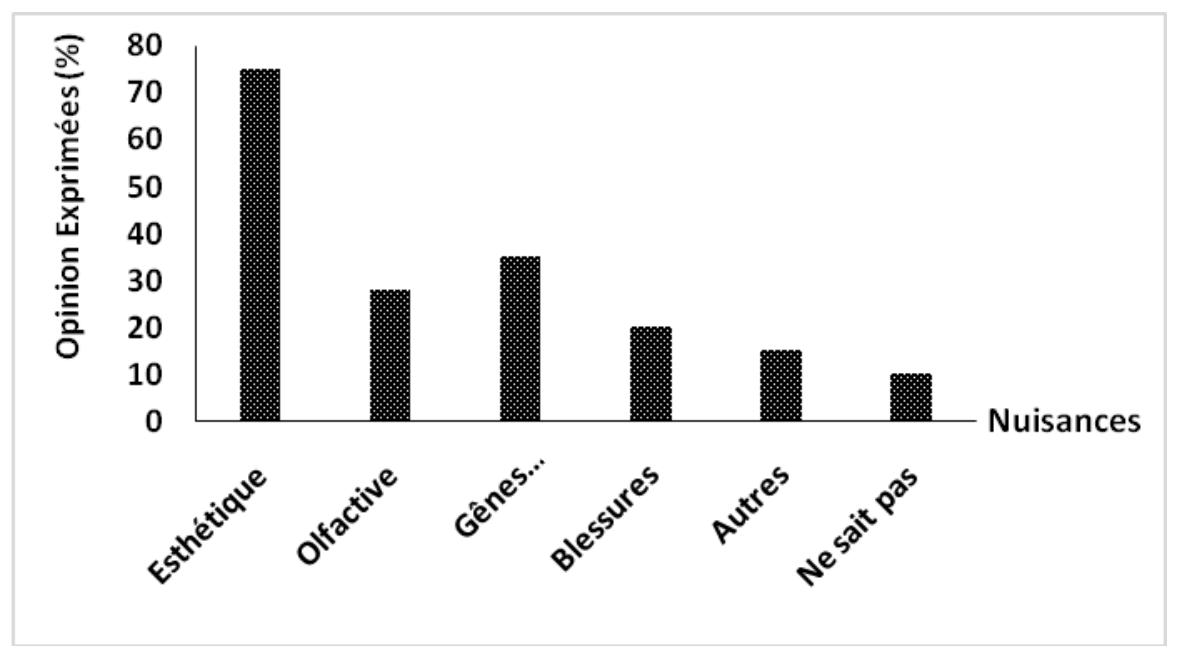

Source: Houngue E., 2016

From the analysis of Figure 3, it emerges that macro-beach waste is the source of several nuisances, first of all aesthetic nuisances since they are a stain. A beach littered with waste of all kinds is obviously detrimental to the image of seaside tourism, especially since tourists are particularly sensitive to the quality of the living environment, in particular clean and healthy coasts to attract a growing number of customers from their vacation spots. Macro waste is also responsible for odor nuisance due to fermentation of organic food or natural waste accompanied by unpleasant odors amplified by the summer heat. This nuisance attracts insects and promotes their proliferation on the shores

The presence of macro-waste also has an impact on human health. This waste, in particular blunt objects (shards of bottles, used syringes or pieces of metal represent a risk of injury for the population frequenting the beaches, in particular for children and fishermen in their activity. These discharges can also be detrimental to the environment reputation of a site, leading to a disaffection of beaches by tourists. Coastal tourism and ecotourism activities and more generally, frequentation of beaches are the sectors most vulnerable to macro-waste. In total, beach waste is considered to have a significant cost for society, especially with regard to tourist and recreational activities linked to the coast (UNEP, 2009).

On the other hand, the international scientific literature also notes positive externalities linked to the presence of macro-waste on the beach. The discharges that run aground on beaches can play an ecological role. On the one hand, they support a complete food chain and serve as habitat for many invertebrates and as a nest and food for birds. On the other hand, these discharges also play a direct geomorphological role because left as they are, they are a bulwark against erosion, and indirect because their decomposition by detritivores and bacteria releases organic matter and 
Vol. 06, No. 03; 2021

ISSN: $2456-8643$

mineral salts which promote the development of flora which stabilizes the dunes by retaining the sand.

\section{CONCLUSION}

In the context of a greater awareness of the place of macro-waste as a source of environmental pollution, this article takes stock of this problem in Benin. It emerges from this reflection that Beninese beaches, like all the others, are confronted with the relatively massive presence of macro-waste. The results of the sparse work provide insight into the gravity of the situation through both the volume and the composition of the deposit of discharges on the beaches, which consist mainly of plastic, glass, and metal. More than mac macro-waste is of land-based origin, generated by users of beaches, landfills, ports, urban and industrial areas, fishing, recreational activities, etc. These seemingly banal discharges represent a unique source of pollution and nuisance from an environmental, health, safety and economic standpoint. However, although visible, the manifestations of this pollution are still poorly understood, as they are neglected by the scientific community and managers of coastal areas. In fact, macro-waste is not taken into account in the waste management policy. No program is defined, neither at the preventive level (awareness raising, monitoring of the deposit), nor at the curative level (shore maintenance). It does not provide for treatment channels either.

The fundamental stake would be to create a dynamic around this problematic of macro-waste by developing a real structural policy for beach management and by involving all the actors concerned at different levels.

\section{REFERENCES}

BURGENMEIER Beat, 2000, Ecological and Social Principles of the Market. Economica, Paris $306 \mathrm{p}$

BARNES David, 2002, Biodiversity, Invasions by marine life on plastic debris. Nature 416, 808 809.

BARNES David et al., 2009, "Accumulation and fragmentation of plastic debris in global environments" Philos. Trans. R. Soc. London Ser. B, Biol. Sci. 364 (1526), 1985-1998.

CANNIZZARO Leonardo GIUSTA G. B, PIETRO Rizzo and LEVI Decio, 1995, Qualitative and quantitative estimate of solid waste in the channel of Sicily. Proceeding of the second conference on the Mediterranean coastal environment. pp. 1409-1416.

DOSSOU-YOVO Coffi Adrien., 2017, Characterization of sea leashes on the beaches of Benin. Regardsuds magazine; Second issue, September 2017, ISSN-2414-4150 Abidjan (Ivory Coast), pp 6-22.

HENRY Maryvonne, 2010, Pollution of the marine environment by solid waste: State of knowledge. Prospects for Ifremer involvement in response to the challenge of the Marine Strategy Framework Directive and the Grenelle de la Mer. 69 p. 
Vol. 06, No. 03; 2021

ISSN: $2456-8643$

HOUNGUE Elisette, 2016, Characterization of beach waste: case of the west coast of Cotonou. Master's thesis, University of Abomey-Calavi, 98 p.

LAÏBI Raoul et al., 2014, "Longshore drift cell development on the human impacted Bight of Benin sand barrier coast, West Africa" In: Green, A.N. and Cooper J.A.G. (eds.), Proceedings 13th International Coastal Symposium (Durban, South Africa), Journal of Coastal Research Special Issue No. 66, pp.

LAIST David, 1997, "Impacts of marine debris: Entanglement of marine life in marine debris, including a comprehensive list of species with entanglement and ingestion records". In Coe, J. M. and D.B. Rogers, (Eds) Marine Debris: Sources, Impacts and Solutions. Springer Verlag, New York, NY, pp. 99-139.

MANSUI Jeremy, 2015, Observation and modelling of macro-waste in the Mediterranean Sea, from the large scale to the coastal and littoral scales. Oceanography. University of Toulon, $174 \mathrm{p}$.

OSPAR, 2007, Monitoring of marine litter in the OSPAR region. OSPAR Commission: pp. 74.

UNEP / PAM / MEDPOL, 2009. Results of the assessment of the status of marine litter in the Mediterranean. Meeting of MED POL Focal Points n ${ }^{\circ} 334,91 \mathrm{p}$.

ROSSI Georges, 1989, "Coastal Erosion in the Gulf of Benin: an example of disturbance of a morpho-dynamic balance". Zeitschrift für Geomorphologie: Supplement bände, 73,139-165.

RYAN Peter, MOORE Charles James, VAN FRANEKER JAN Andries, MOLONEYColeen. (2009), Monitoring the abundance of plastic debris in the marine environment. Phil. Trans. R. Soc. B 364 (1526), pp 1999-2012.

SAFEGE / ADEME, 2012, Study on the characterization and flows of waste in fluvial and marine environments. Phase 1: Identification of actors, 10 p. (plus 50 files); Phase 2: Experience feedback, $231 \mathrm{p}$.

THOMPSON Richard, SWAN Shanna, MOORE Charles, VOM SAAL Frederick, 2009. Our plastic age. Philosophical Transactions of the Royal Society of London B: Biological Sciences 364 (1526), 1973-1976. 